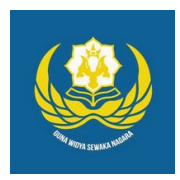

Jurnal Analogi Hukum

Journal Homepage: https://ejournal.warmadewa.ac.id/index.php/analogihukum

\title{
Implementasi Peraturan Walikota Denpasar Nomor 9 Tahun 2009 Tentang Penataan dan Pembinaan Pasar Tradisional, Pusat Perbelanjaan dan Toko Modern
}

\author{
Ni Kadek Diah Sri Laksmi Dewi*, Ni Luh Made Mahendrawati dan Desak Gde Dwi Arini \\ Universitas Warmadewa, Denpasar-Bali, Indonesia \\ *laksmidewi@gmail.com
}

\begin{abstract}
How To Cite:
Dewi, N, K, D, S, L., Mahendrawati, N, L, M., Arini, D, G, D. (2021). Implementasi Peraturan Walikota Denpasar Nomor 9 Tahun 2009 Tentang Penataan dan Pembinaan Pasar Tradisional, Pusat Perbelanjaan dan Toko Modern. Jurnal Analogi Hukum. 3 (1). 22-26. Doi: https://doi.org/10.22225/ah.3.1.3023.22-26

Abstract - he development of the business world in Indonesia is fairly rapid, one of which is a network retail business or minimarket, so it spurs a variety of new problems relating to the practice of business activities in the field. So that the government must be able to make a regulation in order to prevent and overcome problems that will or are arising. The problems of this study are: 1) How to structuring and fostering traditional markets, shopping centers and modern stores based on Denpasar Mayor Regulation Number 9 of 2009 and 2) Does the existence of modern stores lead to monopolistic practices and unfair business competition. The research method used is the method of empirical legal research so that the problem approach used is a sociological or research approach with the aim of obtaining legal knowledge by plunging directly into the objectThe results of the study can be concluded that the Mayor of Denpasar Regulation Number 9 of 2009 concerning the Arrangement and Development of Traditional Markets, Shopping Centers, and Modern Stores does not make clear rules for minimarket businesses, so that if the development of the minimarkets is allowed to continue without any rules binding will become the center of monopolistic practices that have the potential to undermine fair business competition between traditional market traders and modern shop business people as well as between modern store business actors.
\end{abstract}

Keywords: Business Competition; Implementation; Modern Shops

\begin{abstract}
Abstrak - Perkembangan dunia usaha di Indonesia terbilang sangat pesat, salah satunya adalah usaha ritel berjejaring atau minimarket, maka hal tersebut memacu berbagai masalah baru yang berkenaan dengan praktek kegiatan usaha di lapangan. Sehingga pemerintah harus dapat membuat suatu regulasi dalam rangka pencegahan dan penanggulangan permasalahan yang akan atau sedang timbul. Permasalahan dari penelitian ini adalah: 1) Bagaimana penataan dan pembinaan pasar tradisional, pusat perbelanjaan dan toko modern berdasarkan Peraturan Walikota Denpasar Nomor 9 Tahun 2009 dan 2) Apakah keberadaan toko modern menyebabkan terjadinya praktek monopoli dan persaingan usaha tidak sehat. Metode penelitian yang digunakan adalah metode penelitian hukum empiris sehingga pendekatan masalah yang digunakan yaitu pendekatan sosiologis atau penelitian dengan tujuan memperoleh pengetahuan hukum dengan cara terjun langsung ke obyeknya. Adapun hasil dari penelitian dapat disimpulkan bahwa Peraturan Walikota Denpasar Nomor 9 Tahun 2009 tentang Penataan dan Pembinaan Pasar Tradisional, Pusat Perbelanjaan, dan Toko Modern tidak membuat aturan yang jelas untuk usaha minimarket, sehingga jika perkembangan minimarket dibiarkan terus berlanjut tanpa ada aturan yang mengikat maka minimarket akan menjadi pusat praktek monopoli yang berpotensi merusak persaingan usaha yang sehat antara pedagang pasar tardisional dengan pelaku usaha toko modern maupun antar pelaku usaha toko modern.
\end{abstract}

Kata kunci: Persaingan Usaha; Implementasi; Toko Modern 


\section{Pendahuluan}

Pasar dikenal sebagai tempat bertemunya antara penjual dan pembeli. Selain adanya aktifitas perdagangan, pasar juga menjadi tempat berinteraksi sosial (Hakim, 2005). Pasar tradisional sebagai salah satu pusat perekonomian rakyat pada awalnya jumlahnya cukup banyak dan tersebar di setiap daerah di Indonesia.Pasar tradisional juga merupakan representasi dari nilai-nilai kearifan lokal dan bagian dari kebudayaan nasional Indonesia yang harus dilestarikan sebagaimana dijamin dalam Pasal 28 I ayat (3) dan Pasal 32 ayat (1) UUD NRI 1945 (Ariyani, 2019).

Pasar dibagi menjadi dua yaitu pasar tradisional dan pasar modern. Pasar tradisional yang dulunya menjadi pusat bertemunya penjual dan pembeli kini diperbarui oleh pasar modern yang memiliki fungsi sama dengan pasar tradisional. Perkembangan zaman dan perubahan gaya hidup yang dipromosikan begitu hebat oleh berbagai media serta berdirinya pasar modern telah membuat pengaruh besar terhadap pasar tradisional, serta eksistensi pasar tradisional sedikit terusik karena banyaknya konsumen yang lebih memilih belanja di pasar modern (Martin, 2017). Pasar modern atau retail menjual hampir semua kebutuhan rumah tangga dalam bentuk eceran. Ditambah lagi dengan kenyamanan berbelanja di dalam ruangan yang bersih, aman, nyaman, dan lengkap. Sangat jelas mengapa masyarakat beralih untuk memenuhi kebutuhan di toko retail selain kenyamanan dan pelayanan yang diberikan, harga produk tidak jauh berbeda dengan produk yang terdapat pada pasar tradisional. Upaya pembangunan dalam suatu tatanan masyarakat dapat dilakukan dengan kegiatan usaha (Soemarwoto, 2003).

Namun kegiatan usaha yang tidak terkontrol akan menjadikan kegiatan usaha tersebut bukannya menguntungkan namun sebaliknya. Oleh karena itu pemerintah membuat beberapa aturan yang mengatur hal tersebut diantaranya UU No. 5 Tahun 1999, PP No. 112/2007, dan Permendag No. 70/M-DAG/ PER/12/2013.

Setiap daerah harus memiliki aturan tentang ritel modern. Di Kota Denpasar pengaturan mengenai penataan dan pembinaan Pasar Tradisional, Pusat perbelanjaan, dan Toko Modern diatur pada Perwali No 9/2009. Peran pemda sangat diperlukan demi tercapainya keseimbangan kegiatan berusaha. Perkembangan retail modern yang semakin pesat membuat pasar tradisional dan toko kelontong menjadi tersingkir dari arena kegiatan persaingan usaha.

Berdasarkan uraian tersebut diatas maka rumusan masalah yang Akan dibahas adalah:

Bagaimana Penataan Dan Pembinaan Pasar Tradisional, Pusat Perbelanjaan Dan Toko Modern Berdasarkan Peraturan Walikota Denpasar Nomor 9 Tahun 2009?

Apakah keberadaan Toko Modern menyebabkan terjadinya praktek monopoli dan persaingan usaha tidak sehat?

Dalam melakukan suatu penelitian tentu terdapat suatu tujuan yang ingin diperoleh peneliti dan dalam penulisan ini tujuan peneliti adalah:

Untuk menambah pengetahuan dan memperluas wawasan penulis tentang menata dan membina pasar tradisional maupun modern yang diatur dalam Peraturan Walikota Denpasar No 9 Tahun 2009.

Untuk mengetahui pengaruh keberadaan toko modern yang ada di Kota Denpasar menyebabkan terjadinya praktek monopoli atau tidak.

\section{Metode}

Penelitan ini menggunakan tipe penelitian hukum empiris yaitu penelitian yang dimana datanya diperoleh langsung dari masyarakat melalui penelitian lapangan, melalui pengamatan, wawancara dengan pejabat berwenang di Dinas Perijinan dan PTSP, pedagang toko klontong, dan pemilik toko berjejaring. Pendekatan masalah yanag dipergunakan dalam penelitan hukum empiris ini yaitu pendekatan sosiologis hukum dimana penelitian hukum empiris ini diambil berdasarkan facta-facta yanag ada didalam masyarakat, badan hukum atau badan pemerintah.

\section{Hasil Penelitian dan Pembahasan}

Penataan dan Pembinaan Pasar Tradisional, Pusat Perbelanjaan dan Toko Modern berdasarkan Peraturan Walikota Denpasar Nomor 9 Tahun 2009

Di Kota Denpasar pendirian pasar tradisional dibangun sesuai dengan aturan yang berlaku. Penataan dan pembinaan Pasar Tradisional terdapat pada Perwali Denpasar 9/2009. Pendirian pasar tradisional wajib memenuhi beberapa ketentuan (Pasal 2). Dalam 
membangun pasar tradisional yang harus diperhitungkan adalah kondisi sosial ekonomi masyarakat dan melihat keberadaannya termasuk koperasi yang ada di daerah bersangkutan. Areal parkir sangatlah penting sebagai tempat konsumen memarkirkan transportasinya. Areal yang dibutuhkan minimal untuk satu mobil. Dan pendirian pasar tradisional menjamin kebersihan, hygienis, keamanan, ketertiban, dan ruang publik yang nyaman.

Pada pendirian Pasar tradisional, Peraturan Walikota ini juga mengatur cara membina dan mengawasi berjalannya pasar tradisional. Dalam membina pasar tradisional, pemkot berupaya mengumpulkan sumber dana alternatif untuk memberdayakan Pasar Tradisional. Lalu Pemerintah Kota juga meningkatkan kompetensi pedagang dan pengelola Pasar Tradisional. Pemerintah Kota memberikan prioritas kepada pedagang yang sudah berjualan di pasar tersebut lebih dulu sebelum adanya penataan ulang terhadap pasar yang bersangkutan.

Pada penataan pendirian Pusat Perbelanjaan ada beberapa kewajiban yang harus diperhatikan, seperti yang ada pada Pasal 4 Peraturan Walikota Denpasar Nomor 9 Tahun 2009 yaitu harus melihat situasi ekonomi masyarakat, keberadaan Pasar Tradisional, UMKM yang ada di wilayah Denpasar; memperhitungkan jarak antar pasar yang telah ada sebelumnya; menyediakan tempat parkir minimal untuk kendaraan roda empat; dan menyediakan fasilitas yang terjaga kebersihannya, kesehatannya (hygienis), keamanan, ketertiban, dan ruang publik yang nyaman.

Batasan luas lantai penjualan, sistem penjualan dan jenis barang dagangan Toko Modern adalah:

Minimarket, batas luas lantai kurang dari empat ratus meter per segi, menjual barang konsumsi seperti makanan dan minuman dalam bentuk yang lebih kecil lagi;

Supermarket, Toserba, Swalayan, Departement Store dan Mall batas lantai 400m2 (empat ratus meter per segi) dan produk yang dijual serupa dengan minimarket;

Perkulakan batas luas lantainya diatas $5000 \mathrm{~m} 2$ (lima ribu meter per segi) dan menjual secara grosir barang konsumsi.

Pembinaan Pusat perbelanjaan dan Toko Modern oleh Pemerintah Kota mewajibkan untuk mengutamakan kemajuan pasar tradisional dan membina UMKM agar standar masyarakat kecil lebih maju. Dalam mengawasi Pusat
Perbelanjaan dan Toko Modern pemkot mewajibkan untuk memberikan data informasi penjualan sesuai dengan ketentuan yang berlaku. Apabila ada pelanggaran maka dapat dikenakan hukuman administratif secara bertahap mulai dari peringatan tertulis, pembekuan, hingga pencabutan ijin usaha.

\section{Keberadaan Toko Modern Terhadap Praktek Monopoli dan Persaingan Usaha Tidak Sehat}

Meningkatnya tingkat konsumsi dan keinginan berbelanja masyarakat membuat industri retail semakin dilirik oleh para pelaku bisnis. Kata Retail berasal dari Bahasa Perancis Ritellier, yang berarti memotong atau memecah sesuatu (Utami, 2010).

Retail dapat digolongkan menjadi 2 yaitu Retail Tradisional dan Retail Modern. Contoh dari Retai Tradisional adalah toko klontong, kios, los, dan juga toko-toko yang dibuka di depan rumah. Sedangkan contoh Retail Modern adalah Alfamart dan Indomaret. Perbedaan yang sangat terlihat antara Retail Modern dengan Retail Tradisional adalah sistem dan pelayanannya. Kedua perbedaan tersebut membuat Retail Modern maupun Retail Tradisional memiliki kelebihan dan kekurannya masing-masing.

Keunggulan Retail Modern sudah dapat dirasakan masyarakat di era globalisasi ini yaitu kenyamanan berbelanja yang kebersihannya terjaga juga dilengkapi ruangan ber-AC dengan sistem belanja swalayan atau mengambil produk kebutuhan secara mandiri. Kelebihan yang dimiliki Retail Modern tetap memiliki kekurangan dalam keamanan. Dengan sistem berbelanja secara swalayan tidak menutup kemungkinan kecurangan bisa saja dilakukan oleh pembeli yang tidak bertanggung jawab. Lain halnya dengan Retail Tradisional yang walaupun kebanyakan masyarakat menilai Retail Tradisional jauh dari kebersihan dan kenyamanan namun interaksi sosial yang terjadi antara penjual dan pembeli masih sangat hangat dirasa.

Persaingan tidak bisa dipisahkan dari kehidupan manusia. Demi kemajuan meningkatkan kualitas kehidupan manusia, persaingan memanglah membawa manfaat besar. Tetapi disamping itu dampak negatif dari persaingan sangat dirasakan oleh pihak yang kalah dalam suatu persaingan. Agar terhindar dari praktek persaingan usaha tidak sehat maka dibuatlah Undang-undang Nomor 5/1999 Tentang Larangan Praktek Monopoli dan Persaingan Usaha Tidak Sehat. Dalam UU No. 
5 Tahun 1999 terdapat perjanjian-perjanjian yang dilarang. Perjanjian itu adalah Oligopoli,Penetapan Harga,Pembagian Wilayah, Pemboikotan, Kartel, Trust, Oligopsoni, Integrasi Vertikal,Perjanjian Tertutup, dan Perjanjian dengan Pihak Luar Negeri. Selain mengatur tentang perjanjian apa saja yang dilarang, UU No. 5 Tahun 1999 juga mengatur tentang kegiatan-kegiatan yang dilarang. Kegiatan itu adalah Monopoli,Monopsoni,Penguasaan Pasar, dan Persekongkolan.

Bisnis ritel memiliki potensi yang besar sebagai pesaing usaha yang berkembang pesat. Bahkan usaha ini yang dimulai dari syarat sederhana dikarenakan jaringan yang dibuat sangatlah luas membuat usaha toko berjejaring ini maju dan diminati. Hanya dengan modal yang sudah ditetapkan, siapapun bisa menjadi pemilik toko waralaba. Dengan tanpa adanya peraturan yang mengatur tentang bagaimana pembatasan untuk pendirian minimarket ini membuat para pengusaha lebih mudah dalam membuka gerai.

Demikian pula halnya dengan yang terjadi di Kota Denpasar, yang merupakan ibukota dengan tingkat pertumbuhan toko modern yang sangat tinggi jika dibandingkan dengan kabupaten yang ada di Bali. Berdasarkan data yang diperoleh terdapat 295 toko modern yang beroperasi di Kota Denpasar dengan mengantongi ijin. Bahkan diantaranya banyak yang sangat berdekatan pasar tradisional dan juga toko modern lain yang tentu saja hal ini sagat dikhawatirkan mematikan keberlangsungan ekonomi rakyat tersebut.

Di Kecamatan Denpasar Utara kini menjadi daerah yang sangat berkembang. Banyaknya perumahan yang di bangun di daerah ini dikarenakan Kecamatan Denpasar Utara sangatlah strategis yaitu dekat dengan sekolah, rumah sakit, terminal, dan akses lainnya. Oleh karena itu daerah ini menjadi lokasi yang sangat diminati pelaku usaha untuk mendirikan toko modern.

Menurut Ibu Anggreni yang bertugas dalam pembuatan ijin untuk membuka toko minimarket, pembisnis yang ingin membuka usaha toko berjejaring sangatlah kurang informasi mengenai prosedur atau alur bagaimana tata cara yang harus dilakukan dalam membuka gerai toko waralaba. Sehingga para pengusaha tersebut biasanya mencari ijin hanya sampai pada pejabat Desa dimana toko akan dibuka. Karena kepentingan pribadi maupun desa, pejabat desa mengijinkan pengusaha yang ingin membuka toko di wilayah desanya. Menurut pengakuan pemilik usaha toko berjejaring, syarat yang ingin dicari di Dinas Perijinan dan PTSP ialah rumit. Sehingga para pebisnis hanya bermodalkan ramah tamah serta memberikan sedikit kompensasi terhadap warga desa sudah cukup untuk mendirikan tokonya.

Bagi para pedagang toko kelontong atau toko yang dibuka di depan rumah persaingan usaha tidaklah berpengaruh bagi mereka. Karena menurut para pedagang kelontong tersebut warga tetap memilih berbelanja di tempat yang dekat dengan rumahnya. Ditambah lagi biasanya pedagang kelontong menjual produk makanan tradisional yang menjadi andalannya yaitu rujak, tipat, dan berbagai minuman tradisional lainnya yang masih sangat digemari oleh masyarakat. Makanan dan minuman tradisional masih menjadi andalan toko kelontong kebanyakan karena tidak dijual di toko modern manapun.

Penentuan jarak Toko Modern (kecuali minimarket) tidak diperkenankan pada radius kurang dari 1 (satu) kilometer dari Pasar Tradisional. Tetapi kenyataan di lapangan, Indomaret yang berada di Jalan Ahmad Yani No 229 B-C yang tidak mengantongi ijin dan membuka gerainya sangat berdekatan dengan Toko Retail Tradisional yang sudah lama ada yaitu UD.Tiga Putra. UD.Tiga Putra sudah ada sejak tahun 2000, sedangkan Indomaret yang dibangun tepat di depan UD. Tiga Putra ada sejak tahun 2010. Berdasarkan wawancara dengan Pemilik Toko kelontong UD Tiga Putra yaitu Ibu Anik mengatakan bahwa dampak yang dirasakannya setelah adanya Indomaret yang dibuka tepat di depan tokonya, membuat omset penjualannya menurun drastis di tahun pertama. Kemudian tiga tahun setelahnya UD Tiga Putra mulai berinovasi untuk mempertahankan para pelanggannya. Ibu Anik yang bekerjasama dalam kepemilikan 
UD Tiga Putra bersama rekan-rekan mampu mempertahankan kualitas barang dan juga memberikan harga promo di setiap hari raya dan membuat Ibu Anik tidak kehilangan semua pelanggannya.

Berdasarkan wawancara dengan beberapa pemilik tokoritel, perkembangan yang terjadi dalam bersaing di usaha ritel ini memang ada untung dan ruginya. Terlebih lagi modal menjadi yang utama. Untuk mewujudkan kenyamanan bagi masyarakat haruslah dikeluarkan biaya yang lebih dari produk. Seperti AC, Kulkas, CCTV, mesin kasir, dan lampu dengan daya tinggi yang membuat produk terlihat sangat jelas dan menarik.

\section{Simpulan}

Penataan Pasar Tradisional , Pusat Perbelanjaan, dan Toko Modern berdasarkan Peraturan Walikota Denpasar Nomor 9 Tahun 2009 wajib mengacu pada Rencana Tata Ruang Wilayah, dan Rencana Detail Tata Ruang termasuk Peraturan Zonasinya.Pembinaan dan Pengawasan Pasar Tradisional, Pusat Perbelanjan dan Toko Modern dilakukan oleh Pemerintah Kota Denpasar untuk mengupayakan sumber-sumber alternatif pendanaan guna memprioritaskan UMKM atau pedagang Pasar Tradisional dengan merenovasi atau merelokasi Pasar Tradisional agar kompetensi pedagang dan pengelola Pasar Tradisional semakin meningkat.

Keberadaan Toko Modern atau bisnis ritel memang sangat menguntungkan dan diminati sehingga menimbulkan persaingan yang luar biasa, persaingan yang menjadi permasalahan baru bagi toko bermodal kecil adalah pesatnya pertumbuhan minimarket dengan sistem waralaba. Ini karena kebiasaan belanja masyarakat berbelanja di tempat yang bersih dan ber $\mathrm{AC}$ atau minimarket memberikan kenyamanan dan kebebasan berbelanja yang lebih. Jika tetap dibiarkan maka tidak menutup kemungkinan akan terjadi praktek monopoli dan persaingan usaha tidak sehat antar minimarket.

\section{DAFTAR BACAAN}

Ariyani, N. (2019). Penataan Pasar-Pasar Tradisional di Indonesia Berdasarkan Teori "Von Stufennaufbau De Rechtsordnung." Jurnal Ilmiah Galuh Justisi, 7(2). Retrieved from https:// jurnal.unigal.ac.id/index.php/ galuhjustisi/article/view/2667
Hakim, M. A. (2005). Menguasai Pasar Mengeruk Untung. Jakarta: PT. Krisna Persada.

Martin, I. (2017). Penerapan Kebijakan Zonasi Dalam Penataan Pasar Tradisional dan Pasar Modern Kota Bandung (Suatu Tinjauan Yuridis dari Perspektif Otonomi Daerah). Wawasan Yuridika, 1(2). Retrieved from http:// ejournal.sthb.ac.id/index.php/jwy/ article/view/131

Soemarwoto, O. (2003). Analisis Mengenai Dampak Lingkungan. Yogyakarta: Gadjah Mada Univ.Press.

Utami, C. W. (2010). Manajemen Ritel: Strategi dan Implementasi Operasional Bisnis Modern di Indonesia. Jakarta: Salemba Empat. 